\title{
Ageing assessment of transformer paper insulation through post mortem analysis
}

\begin{abstract}
A post mortem analysis of scrapped transformers provides an opportunity to directly measure the properties of in-service aged paper insulation. Investigations on 10 scrapped $275 \mathrm{kV}$ and $400 \mathrm{kV}$ power transformers were carried out, where Tensile Index (TI) and Low Molecular Weight Acid (LMA) of the paper insulation sampled from various locations were measured. Multiple-layer TI profile demonstrated the effect of oxidized oil on paper ageing which was confirmed by laboratory ageing experiments. It is LMA rather than High Molecular Weight Acid (HMA) that accelerates the paper degradation. LMA acts as the paper ageing accelerator and also as the paper degradation by-product, supporting the view that self-accelerated hydrolysis process is the main paper ageing mechanism. Finally, a generic relationship between LMA in paper and TI of paper was revealed based on both in-service and laboratory ageing data, i.e. the lower the TI of paper, the higher value of LMA in paper is measured. It implies that LMA in oil can be a potential paper ageing indicator pro viding a link between LMA in oil and paper is found.
\end{abstract}

Keyword: Power transformer; Scrapping; Post mortem analysis; Paper; Oil; Tensile strength; Tensile index; Low molecular weight acid; Ageing; End-of-life 